\title{
C-H Borylation: No Need to Stop for Directions
}

DOI:

10.1016/j.trechm.2020.07.009

\section{Document Version}

Accepted author manuscript

Link to publication record in Manchester Research Explorer

\section{Citation for published version (APA):}

Osborne, H. C., Durie, A., Schmidt, C. K., \& Larrosa, I. (2020). C-H Borylation: No Need to Stop for Directions. Trends in Chemistry. https://doi.org/10.1016/j.trechm.2020.07.009

\section{Published in:}

Trends in Chemistry

\section{Citing this paper}

Please note that where the full-text provided on Manchester Research Explorer is the Author Accepted Manuscript or Proof version this may differ from the final Published version. If citing, it is advised that you check and use the publisher's definitive version.

\section{General rights}

Copyright and moral rights for the publications made accessible in the Research Explorer are retained by the authors and/or other copyright owners and it is a condition of accessing publications that users recognise and abide by the legal requirements associated with these rights.

\section{Takedown policy}

If you believe that this document breaches copyright please refer to the University of Manchester's Takedown Procedures [http://man.ac.uk/04Y6Bo] or contact uml.scholarlycommunications@manchester.ac.uk providing relevant details, so we can investigate your claim.

\section{OPEN ACCESS}




\title{
$\mathrm{C}-\mathrm{H}$ borylation: no need to stop for directions
}

\author{
Hugh C. Osborne ${ }^{1,2}$, Alastair Durie ${ }^{1}$, Christine K. Schmidt, ${ }^{2}$ and Igor Larrosa ${ }^{1, *}$ \\ ${ }^{1}$ Department of Chemistry, School of Natural Sciences, University of Manchester, Oxford Road, \\ Manchester M13 9PL, UK \\ ${ }^{2}$ Manchester Cancer Research Centre, Oglesby Building, 555 Wilmslow Rd, Manchester M20 4GJ, \\ United Kingdom \\ * Correspondence: Igor Larrosa (igor.larrosa@manchester.ac.uk)
}

\begin{abstract}
A recent work by Hartwig et al. (Science, 2020) details an efficient method to borylate strong primary $\mathrm{C}\left(\mathrm{sp}^{3}\right)-\mathrm{H}$ bonds via iridium-catalysed $\mathrm{C}-\mathrm{H}$ activation. The conditions confer counterintuitive selectivity over more labile $\mathrm{C}-\mathrm{H}$ bonds, while providing an avenue for a gamut of synthetically valuable late-stage functionalisations through versatile borylate intermediates.
\end{abstract}

Key words $\mathrm{C}-\mathrm{H}$ bond activation; borylation; late-stage functionalisation; iridium; undirected;

In recent years, the field of $\mathrm{C}-\mathrm{H}$ activation has expanded rapidly. Its promise is clear; a pinpoint approach to organic chemistry in which an otherwise unreactive bond is selectively cleaved to install a desired functional group (FG) in its place. This enables the contemporary chemist to contemplate increasingly step-efficient synthetic routes, with divergence towards desired analogues occurring at a later stage of the synthesis. Furthermore, late-stage functionalisation provides novel tools to explore yet-unexploited chemical space. However, due to low intrinsic reactivity, strategies targeting less labile bond types, such as aliphatic and, particularly, primary $\mathrm{C}-\mathrm{H}$ bonds, are much less abundant [1-3].

Regioselectivity is often achieved in the presence of a coordinating directing group, which acts as an internal ligand, guiding (or directing) a transition metal catalyst intramolecularly to the target $\mathrm{C}-\mathrm{H}$ bond [4]. However, if the directing group is not integral to the substrate's structure, it must be installed and then removed, consequently reducing a synthetic route's step-efficiency.

$\mathrm{C}\left(\mathrm{sp}^{3}\right)-\mathrm{H}$ borylation approaches have historically received less attention than those targeting, in a directed or undirected manner, their more labile $\mathrm{C}\left(\mathrm{sp}^{2}\right)-\mathrm{H}$ bond counterparts [5-8]. Undirected methods towards primary $\mathrm{C}-\mathrm{H}$ bond borylation are particularly scarce, and have typically required a large excess of substrate and shown poor FG tolerance, restricting their utility $[6,8]$.

Given the paucity of viable methods for the borylation of strong alkyl C-H bonds, the recent work from the Hartwig group at Berkeley is an enticing contribution [6]. Building on a number of papers exploring increasingly active iridium catalyst systems, the Hartwig group now demonstrate a highly efficient and selective undirected borylation of primary alkyl $\mathrm{C}-\mathrm{H}$ bonds.

Hartwig and colleagues have pushed the envelope by designing successive ligands to complement their existing iridium catalyst complex. Building on a prolific ligand, 4,4'-di-tert-butylbipyridine (dtbpy), the Hartwig group had previously developed a 3,4,7,8-tetramethylphenanthroline (tmphen) ligand $[5,7]$. The added rigidity of this ligand promoted complex stability, preventing dissociation and subsequent $\mathrm{C}-\mathrm{H}$ borylation of the ligand, a major pathway in catalyst deactivation. The resultant 
catalyst complex demonstrated superior conversion of aryl and heteroaryl substrates. It also mediated the borylation of aliphatic $\mathrm{C}-\mathrm{H}$ bonds and exhibited amine, ether and silane FG tolerance [5].

Until the most recent publication, the principal focus for further ligand development resided on six positions on the phenanthroline scaffold (3-8). The underlying rationale was to modulate electronic effects at the iridium centre without perturbing the steric environment [5, 8]. Substituent modification at the less-explored 2 and 9 positions on an otherwise unaltered phenanthroline frame confounded researchers (figure 1). Methylating both positions in the ligand led to comparable rates of product formation as tmphen when used to borylate tetrahydrofuran (THF - neat, $100{ }^{\circ} \mathrm{C}$ ) as a benchmark. Strikingly, a 2-methylphenanthroline (2-mphen) ligand resulted in an 80-fold increase in the rate of product formation. With a dramatic effect on reaction rate and substrate conversion, these findings were placed in even starker contrast with previous ligands when kinetic isotope effect (KIE) experiments suggested that the active catalyst complex may in fact be borylated at the C2 methyl. Borylation of the ligand was previously determined to be a cause of catalyst deactivation, at aromatic and benzylic positions in tmphen [5].

These unexpected observations led to the elaboration of an expansive scope of borylation in which substrates can now be used as limiting reagents at reduced concentrations (figure 1). When presented with a variety of primary, secondary, and tertiary $\mathrm{C}-\mathrm{H}$ bonds, the catalyst complex selectively borylated primary $\mathrm{C}-\mathrm{H}$ bonds. In the absence of primary $\mathrm{C}-\mathrm{H}$ bonds, such as in saturated carbocycles or heterocycles, strong secondary $\mathrm{C}-\mathrm{H}$ bonds were selectively functionalised instead. Hartwig complements a sizeable scope with further KIE analyses, establishing that $\mathrm{C}-\mathrm{H}$ bond cleavage is irreversible and responsible for the observed selectivity for primary bonds. This is in contrast to previous Rh-catalysed methods where the selectivity was determined at the C-B bond formations step [6].

In the presence of multiple primary aliphatic $\mathrm{C}-\mathrm{H}$ bonds, modification of sterically hindered positions was found to be disfavoured $(\mathbf{1}, \mathbf{3})$, while heteroatom proximity informed product ratios in resulting mixtures $(\mathbf{2} \mathbf{a} / \mathbf{b})$. The position at which carbocycles were altered depended predominantly on accessibility. Ring geometry influenced functionalisation such that the most distal $\mathrm{C}-\mathrm{H}$ bonds were altered, at times tendering a stereoselective transformation $(\mathbf{4}, \mathbf{5})$.

Uncommonly, $\mathrm{C}-\mathrm{H}$ bonds beta to heteroatoms $(\mathrm{O}, \mathrm{N})$ in ring systems were selectively modified over the alpha position, the latter being more typical due to bond strength (6-8). The mechanism of this selectivity is still to be determined. Sakaki has postulated that a large energy barrier to reductive elimination alpha to the heteroatom prevents successful borylation [9]. While in a previous publication, Hartwig and colleagues discussed the prospect of interligand (boryl-phenanthroline) non-covalent interactions facilitating oxidative addition beta to the heteroatom [8].

In comparison to past approaches, FG tolerance was significantly improved. Substrates featuring ether, silyl ether, imide, carbamate, amine, ketal and acetal functionality were successfully transformed, while aldehydes and ketones were not tolerated. Equally, alcohol FGs were compatible provided that the alcohol substrate was protected by premixing with HBpin prior to the reaction (4, 7).

This work constitutes an elegant solution to the functionalisation of inherently inert $\mathrm{C}-\mathrm{H}$ bonds with remarkable selectivity and FG tolerance, for which there is a relative dearth of viable approaches. 
Nonetheless, broad applicability to late stage borylation of more complex molecules bearing various functionalities is still to be shown. Equally, the wider application of this method is likely dependent on the characterisation of the active catalyst complex, and further ligand optimisation. While boryl moieties feature in a small minority of pharmaceutical compounds, notably bortezomib (Velcade) and daughter compounds, boryl intermediates are a gateway to a plethora of derivatisation methods [10]. The versatility of boryl substituents lies in their further accessible modification through oxidation, amination, halogenation, arylation, vinylation, homologation, cross-coupling methods, which were demonstrated in this work (figure 2). This approach has the potential to serve as a multipurpose tool for the synthetic chemist, allowing the selective installation of complex, valuable FGs at a late stage.

\section{References}

1. Qin, Y. et al. (2017) Organocatalysis in Inert C-H Bond Functionalization. Chem. Rev. 117, 9433-9520.

2. Cernak, T. et al. (2016) The medicinal chemist's toolbox for late stage functionalization of drug-like molecules. Chem. Soc. Rev. 45, 546-576.

3. Yamaguchi, J. et al. (2012) C-H Bond Functionalization: Emerging Synthetic Tools for Natural Products and Pharmaceuticals. Angew. Chemie 51, 8960-9009.

4. Sambiagio, C. et al. (2018) A comprehensive overview of directing groups applied in metalcatalysed C-H functionalisation chemistry. Chem. Soc. Rev. 47, 6603-6743.

5. Oeschger, R. J. et al. (2019) Origin of the Difference in Reactivity between Ir Catalysts for the Borylation of C-H Bonds. J. Am. Chem. Soc. 141, 16479-16485.

6. Oeschger, R. et al. (2020) Diverse functionalization of strong alkyl C-H bonds by undirected borylation. Science 368, 736-741.

7. Liskey, C. W. and Hartwig, J. F. (2012) Iridium-Catalyzed Borylation of Secondary C-H Bonds in Cyclic Ethers. J. Am. Chem. Soc. 134, 12422-12425.

8. Larsen, M. A. et al. (2020) Effect of Ligand Structure on the Electron Density and Activity of Iridium Catalysts for the Borylation of Alkanes. ACS Catal. 10, 3415-3424.

9. Zhong, R.-L. and Sakaki, S. (2019) sp3 C-H Borylation Catalyzed by Iridium(III) Triboryl Complex: Comprehensive Theoretical Study of Reactivity, Regioselectivity, and Prediction of Excellent Ligand. J. Am. Chem. Soc. 141, 9854-9866.

10. Manasanch, E. E. and Orlowski, R. Z. (2017) Proteasome inhibitors in cancer therapy. Nature Reviews Clinical Oncology vol. 14 417-433. 


\section{Figure 1}

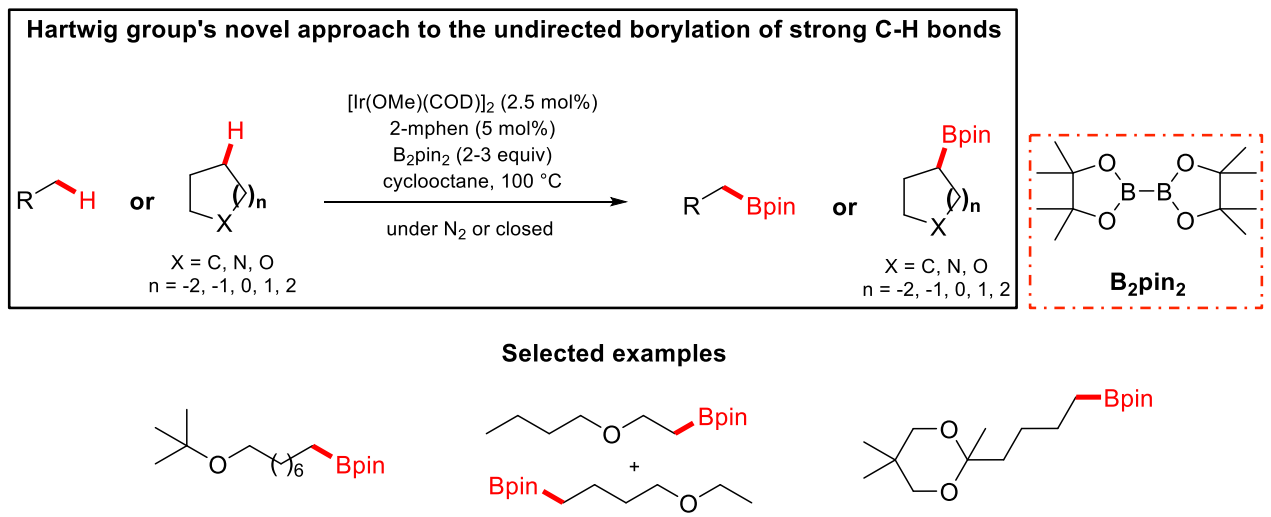
$1,62 \%(51 \%)$
2a/b, $71 \%(51 \%, 9: 1)$
3, $81 \%(54 \%)$

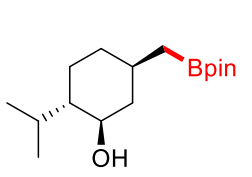

4, $49 \%$ *

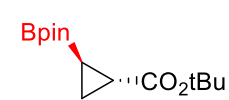

5, $90 \%(53 \%)$

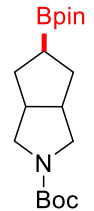

6, $37 \%$ d.r. $=2.5: 1$<smiles>OCC1CC(Br)CO1</smiles>

$7,41 \%$<smiles>O=C(N1CCCCC(Cc2ccccc2)C1)C(F)(F)Br</smiles>

$8,26 \%$

Ligand design<smiles>CC(C)(C)c1ccnc(-c2cc(C(C)(C)C)ccn2)c1</smiles><smiles>Cc1cnc2c(ccc3c(C)c(C)cnc32)c1C</smiles><smiles>Cc1ccc2ccc3cccnc3c2n1</smiles>

dtbpy

2-mphen

Increasing reaction rate, product conversion, and altered selectivity

Figure 1. Novel conditions presented by Hartwig et al. towards the undirected borylation of strong $\mathrm{C}-\mathrm{H}$ bonds. Yields are presented above followed by the corresponding isolated yield in parentheses. Asterisk-marked yield represents the resultant yield following oxidation of the boryl moiety to the corresponding alcohol where the alkylboronate could not be isolated. $t \mathrm{Bu}$, tert-butyl; d.r., diastereomeric ratio; dtbpy, 4,4'-di-tert-butylbipyridine; tmphen, 3,4,7,8tetramethylphenanthroline; 2-mphen, 2-methylphenanthroline. 
Figure 2

Diverse derivatisation methods of $\mathrm{C}-\mathrm{H}$ borylation products

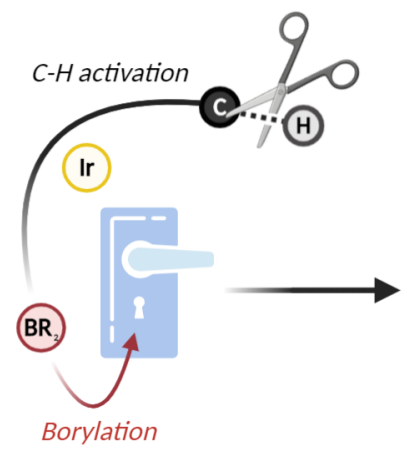

Borylation
Oxidation

Amination

Halogenation

Arylation

Vinylation

Homologation
Facile late-stage

functionalisation

towards valuable

compounds

Cross-coupling

Figure 2. Schematic representing the diverse derivatisation methods of $\mathrm{C}-\mathrm{H}$ borylation products shown by Hartwig et al. Spheres of different colours represent carbon ( $\mathrm{C}$; black), hydrogen $\left(\mathrm{H}\right.$; grey), iridium (Ir; yellow), and boron (BR ${ }_{2}$; red). 